\title{
Entre Habermas e Derrida: Honneth e a tensão entre princípios de justiça no campo de aplicação do Direito ${ }^{1}$
}

Resumo: O presente artigo retoma criticamente a discussão entre a perspectiva universalista da ética do discurso e a perspectiva assimétrica do cuidado da ética desconstrucionista, na forma como ela foi primeiramente analisada por Axel Honneth em seu "The Other of Justice", de 1994. Contudo, divergindo da leitura honnethiana, este artigo desenvolve a tese de que a tensão insolucionável, mas produtiva, entre igualdade de tratamento e cuidado, por ele defendida, também pode ser adequadamente apreendida no campo de aplicação do Direito, oferecendo novos elementos para uma crítica das instituições e das práticas jurídico-discursivas.

Palavras-chave: Teoria crítica; Universalismo moral; Cuidado; Reconhecimento. Direito.

Between Habermas and Derrida: Honneth and the tension between principles of justice in the field of Law enforcement

\begin{abstract}
This article critically resumes the discussion between the universalist perspective of discourse ethics and the asymmetric perspective of care of deconstructionist ethics, as it was first analyzed by Axel Honneth in his "The Other of Justice", of 1994. However, departing from the Honnethian reading, this paper develops the thesis that the unsolvable but productive tension between equal treatment and care, which he defends, can be properly apprehended in the field of Law enforcement as well, providing new elements for a critique of legal-discursive institutions and practices.
\end{abstract}

Keywords: Critical theory; Moral universalism; Care; Recognition; Law.

\footnotetext{
${ }^{1}$ Recebido em 15/08/2016 e aprovado em 03/02/2017.

${ }^{2}$ Mestrando em Filosofia e Teoria Geral do Direito pela Universidade de São Paulo (USP). Contato: jonvfm@gmail.com.
} 
|154 |

Entre Habermas e Derrida:...

Entre Habermas y Derrida: Honneth y la tensión entre principios de justicia en el campo de aplicación del Derecho

Resumen: El presente artículo retoma de manera crítica la discusión entre la perspectiva universalista de la ética del discurso y la perspectiva asimétrica del cuidado de la ética deconstruccionista, de la manera en que Axel Honneth la analizó inicialmente en "The Other of Justice", de 1994. Sin embargo, divergiendo de la lectura honnethiana, este artículo desarrolla la tesis de que la tensión insoluble, aunque productiva, entre igualdad de tratamiento y cuidado, por él defendida, también se puede aprehender adecuadamente en el campo de aplicación del Derecho, ofreciendo nuevos elementos para una crítica de las instituciones y de las prácticas jurídico-discursivas.

Palabras clave: Teoría crítica. Universalismo moral. Cuidado. Reconocimiento. Derecho.

\section{Introdução ${ }^{3}$}

No artigo intitulado "The Other of Justice: Habermas and the Ethical Challenge of Postmodernism" (2007b), ${ }^{4}$ Axel Honneth dedicou-se à tarefa de reconstruir alguns modelos éticos de autores relacionados à filosofia pós-moderna, buscando contrastá-los com categorias fundamentais do cognitivismo moral kantiano, especialmente com aquelas sustentadas por uma de suas principais herdeiras no contexto da segunda metade do século $X X$, a ética do discurso de Jürgen Habermas. ${ }^{5}$ A pretensão de Honneth era com isso verificar quais dentre as alternativas investigadas conseguiriam de fato se colocar como um desafio ao universalismo discursivo-igualitário, tendo em vista sua avaliação preliminar

\footnotetext{
${ }^{3}$ Agradeço aos editores e pareceristas anônimos pelas críticas e sugestões, fundamentais para que este texto chegasse a um nível mais elevado de profundidade e clareza.

${ }^{4}$ Esse artigo apareceu primeiramente em alemão, em 1994, na revista Deutsche Zeitschrift für Philosophie, e, em inglês, em White (1995).

${ }^{5}$ A “ética do discurso" é um modelo filosófico originalmente concebido por Karl-Otto Apel (2004) e Jürgen Habermas (2001; 2003), que no decorrer do tempo tomaram certa distância em suas formulações conceituais, tendo o segundo, inclusive, substituído o termo "ética do discurso" por "teoria do discurso". Para um panorama geral dessa discussão, ver Cenci (2012).
} 
de que a maioria delas poderia ser acomodada no interior dos parâmetros normativo-conceituais habermasianos.

Nesse processo, depois de percorrer as obras de JeanFrançois Lyotard e Stephen K. White, ele alcança os escritos éticos tardios de Jacques Derrida, onde este filósofo descontrucionista, esboçando, por um lado, uma séria dívida com relação aos desenvolvimentos de Emmanuel Levinas e, por outro, tomando certa distância de posicionamentos sustentados em trabalhos anteriores, teria exposto sua versão positiva e dualista da ideia de justiça, que, na visão de Honneth, congregaria elementos suficientes para balançar os alicerces normativos sustentadores da tradição kantiana. Para o teórico crítico, a proposta de Derrida se destacaria com relação às demais por não se limitar à repisada defesa de uma abertura ao particular, ao "outro concreto", buscando, genuinamente, oferecer uma perspectiva ética que, contrariando o igualitarismo kantiano, traria a imposição assimétrica de obrigações entre os sujeitos da relação moral.

A ênfase nos méritos dessa proposta, não obstante, é contrabalanceada por Honneth com algumas considerações de conteúdo crítico, interessando aqui sua objeção quanto ao fato de Derrida caracterizar a tensão entre justiça e cuidado no interior do campo de aplicação das normas jurídicas. Na ótica do filósofo do reconhecimento, os próprios fundamentos normativos do Direito já ofereceriam mecanismos capazes de permitir "a realização de justiça para a particularidade de uma situação extremamente difícil, sem com isso invalidar a norma básica do igual tratamento no processo" (HONNETH, 2007b, p. 122, nossa tradução). Nesse sentido, Honneth argumenta que entre o princípio da igualdade de tratamento e o princípio do cuidado se estabeleceria uma relação de "exclusividade recíproca", de modo que somente se poderia falar no dever de cuidado irrestrito frente ao outro concreto diante de circunstâncias onde a pessoa individual não pudesse participar de discursos práticos, permitindo a conclusão de que, para ele, tanto os discursos de justificação - processos de formação de opinião e vontade políticas - como os de aplicação jurídico-normativa - 
atividade judicial - devem ter sua lógica de desenvolvimento restrita à igualdade de tratamento.

Embora não se discorde em linhas gerais da proposta de análise de Honneth, a tese que se buscará defender neste artigo é a de que a tensão entre os princípios da justiça, percebida por Derrida e atualizada pelo teórico crítico, pode ser adequadamente reconstruída como um conflito insolucionável e produtivo entre princípios de reconhecimento no interior do próprio campo jurídico, sem que isso leve ao rompimento do sentido universalista da validade das normas jurídicas. Nesse sentido, argumenta-se que essa releitura poderá proporcionar uma apreensão mais complexa das bases normativas e, se poderia dizer também, emancipatórias, que estruturam os contextos de decisão sobre a adequabilidade do Direito, ainda oferecendo novos elementos para uma crítica das instituições e das práticas discursivas envolvidas nessa esfera.

Para atingir esse objetivo, primeiramente será retomada a reconstrução empreendida por Habermas acerca dos fundamentos normativos do Direito Moderno, assim como suas repercussões para a definição da universalidade - igualdade - jurídica. Na segunda seção, recuperar-se-ão alguns elementos importantes do modelo ético de Derrida, juntamente com sua reconstrução honnethiana, sendo esta submetida a algumas problematizações. Na última parte se procederá propriamente a uma atualização da base normativa conflituosa presente no campo de aplicação de normas jurídicas, com vistas a evidenciar novas perspectivas para uma teoria crítica dos discursos de aplicação do Direito.

\section{1. Ética do discurso habermasiana e justiça}

Talvez um dos legados mais significativos deixados pelo cognitivismo moral kantiano para a ética do discurso seja a posição de destaque que o chamado "ponto de vista moral" - ou da imparcialidade - recebe em sua cadeia de conceitos e princípios teórico-normativos. Juntamente com ele, permanece a pressuposição de que em sociedades pós-tradicionais não seria 
mais possível o recurso à "moldura fixa do ethos - concreto e com força de obrigação geral - de uma comunidade mais ou menos homogênea" (HABERMAS, 2004, p. 297) a fim de se obter soluções justas para os conflitos de interesse, ou para o estabelecimento de normas legítimas de convivência social. Em face da pluralização de formas de vida coletivas e de projetos de vida individuais, a própria noção de justiça deve assumir, para essa vertente, dimensões cada vez mais abstratas e reflexivas em relação a valores e interesses de comunidades particulares, convicção que a conduziu até sua conformação em alicerces fundamentalmente procedimentalistas.

No entanto, muitos foram os avanços com relação àquela matriz, devendo-se chamar atenção, em vista dos propósitos deste artigo, para a forma particular com que Habermas conduz a reconstrução dos fundamentos normativos do Direito moderno, assim como suas repercussões para a compreensão da universalidade - igualdade - jurídica. Esse processo, na versão tardia do modelo ético-discursivo habermasiano (HABERMAS, 2001), pode ter sua execução resumida em dois movimentos. Primeiramente, o filósofo do discurso assume a consideração sociológica de que, na transição para a modernidade, a quebra do ethos social global, em que estavam fundidos Direito, moral e ética particular, desencadeia nessas esferas processos de diferenciação cultural e social. "No nível do saber cultural se separam [...] as questões jurídicas das questões morais e ético-políticas. No nível institucional, o Direito positivo se desvincula dos usos e costumes, que se encontram reduzidos a puras convenções" (HABERMAS, 2001 , p. 171 , n.t.).

Segundo Habermas, nesse contexto social modificado, embora Direito e moral racional possuam um âmbito comum de problemas para cuidar, como os relacionados ao estabelecimento de ordens sociais legítimas, ou à solução de conflitos de ação "sob o pano de fundo de princípios normativos e regras intersubjetivamente reconhecidos" (HABERMAS, 2001, p. 171, n.t.), seus mecanismos respectivos de abordagem e tratamento apresentam configurações distintas. Enquanto a moral se consolida 
|158|

Entre Habermas e Derrida:...

como mais uma forma de saber cultural, o Direito assume a dupla condição de saber cultural e de sistema de ação; "cabe entendê-lo como um texto de proposições e interpretações normativas, mas também como instituição, quer dizer, como um complexo de elementos reguladores da ação" (HABERMAS, 2001, p. 180, n. t.). Ainda segundo a compreensão habermasiana, diferentemente das normas morais, as normas jurídicas positivas não se dirigem às pessoas em sua individualidade insubstituível, não levam em conta sua trajetória particular de vida ou suas motivações e convicções pessoais. Embora não deixe de regular as ações entre pessoas concretas, o Direito, da perspectiva dos destinatários de seus comandos, somente as concebe sob sua dimensão abstrata de sujeitos de direito, a qual ele próprio lhes atribui. Nesse passo, apenas os efeitos externos das ações recíprocas entre sujeitos de direito são alcançados pelas normas jurídicas, que garantem a efetividade de suas imposições mediante a previsão de sanções, atributo funcional conhecido como coercibilidade.

Sob um prisma normativo-reconstrutivo, todavia, a perda de garantias metafísicas de legitimidade da ordem jurídica não teria feito desaparecer aquele "momento de incondicionalidade (de não-instrumentalização) contido na pretensão de legitimidade do Direito" (HABERMAS, 2001, p. 136, n.t). Esse processo, que Habermas, acompanhandoMaxWeber, denominadesencantamento das imagens religiosas de mundo, apenas haveria provocado uma "reorganização da validade jurídica ao ancorar os conceitos básicos da moral e do direito, de forma simultânea para ambos, sob um nível pós-convencional de fundamentação" (HABERMAS, 2001, p. 136, n.t.). ${ }^{6}$ Portanto, a aproximação entre esses âmbitos

\footnotetext{
${ }^{6}$ É preciso mencionar aqui a defesa habermasiana de uma relação de complementariedade entre Direito positivo e moral moderna a partir de uma ótica sociológicofuncional. Segundo ele, dentre as funções de coordenação social e estabilização de expectativas do Direito moderno concorreria ainda a atribuição de compensar as debilidades de uma moral que, por ter restringida sua esfera de abrangência ao campo do saber cultural, é marcada por incertezas quanto à transferência desse saber reflexivo para o campo da ação. Tal abordagem, contudo, que é complexamente desenvolvida
} 
sócio-normativos ainda se verificaria a partir da base procedimental de sua legitimidade, correspondente aos pressupostos discursivos de avaliação de pretensões de validade problematizadas - cuja projeção dá os contornos do princípio estruturante da ética do discurso habermasiana, o princípio do discurso (HABERMAS, 2001, p. 172; HULSHOF, KEINERT e MELO, 2008, p. 86); porém se distinguindo com relação a seus conteúdos de legitimação, haja vista que, na análise de Habermas (2001, p. 219):

\begin{abstract}
diferentemente da moral, o Direito não regula contextos de interação em geral, mas serve de meio para a auto-organização de comunidades jurídicas que, sob determinadas circunstâncias, se afirmam em seu ambiente social. Com isto imigram ao interior do Direito conteúdos concretos e pontos de vista teleológicos. Enquanto as regras morais, ao se concentrarem no que é interesse de todos por igual, expressam uma vontade absolutamente geral, as regras jurídicas expressam também a vontade particular de uma determinada comunidade jurídica. E enquanto a vontade moralmente livre, de certo modo, permanece virtual, pois tão somente diz o que racionalmente poderia ser aceito por qualquer pessoa, a vontade política de uma comunidade jurídica, que certamente deve estar em consonância com o que é moralmente exigível, é também expressão de uma forma de vida intersubjetivamente compartilhada, de certas constelações de interesses e de finalidades eleitas pragmaticamente (HABERMAS, 2001, p. 219, n.t.).
\end{abstract}

Essa amplitude de conteúdos conformadores da validade jurídica exigiria, por conseguinte, que as argumentações levadas a cabo nos processos de produção e de aplicação legislativa estivessem abertas a diversas ordens de razões - morais,

por Habermas, será omitida neste trabalho, para o qual basta a recuperação da perspectiva normativo-reconstrutiva. 
| 160 |

Entre Habermas e Derrida:..

ético-políticas e pragmáticas - de acordo com a classe de problemas concretos emergentes em cada comunidade política. O leque de temas com que têm de lidar os participantes da esfera pública não se reduziria a questões de autodeterminação de sujeitos morais, mas diria respeito também a tentativas de entendimento coletivo sobre formas concretas de vida, assim como a compromissos sobre interesses particulares não suscetíveis de generalização. É com fundamento nessas considerações que Habermas chega à sua pretensiosa tese de que na seara jurídica o princípio do discurso não está especificado sob a forma interna de uma regra de avaliação de conteúdos morais, mas de um princípio democrático, que apenas determinaria o modo externo pelo qual se torna possível institucionalizar racionalmente a formação pública da opinião e da vontade dos cidadãos, "a saber, mediante um sistema de direitos fundamentais que confira a cada um a igual participação neste processo de produção de normas jurídicas, que esteja, por sua vez, garantido no que se refere aos pressupostos discursivos" (HABERMAS, 2001, p. 176, n.t.).

Apesar de haver essa dissonância de determinações legitimatórias, Habermas ainda defende que a similaridade estrutural entre moral e Direito não estaria limitada à racionalidade procedimental-comunicativa dos pressupostos pós-convencionais de justificação, alcançando contornos mais substanciais ligados ao sistema de direitos fundamentais balizadores da dinâmica de desenvolvimento do ordenamento jurídico nos Estados democráticos de Direito, do qual as atividades legislativa e judicial representariam mecanismos de concretização. Tais direitos carregariam em seu conteúdo histórico-semântico um ideal de universalidade subjacente à pretensão normativa de igualdade de tratamento - cuja origem conceitual remete à tradição do liberalismo político - correspondendo, de um lado, à clássica noção de igualdade jurídica ou igualdade na aplicação das leis, no sentido de não se admitir discriminações ou privilégios quanto aos destinatários dos comandos jurídicos; e, de outro, manterse-ia atrelada à pretensão universal de regular uma matéria no interesse de todos os afetados por igual, que no campo jurídico 
adquire maior alcance em função da maior complexidade dos critérios argumentativos orientadores da justificação da validade de normas jurídico-estatais.

Esta última dimensão da universalidade jurídica consubstanciaria o princípio da igualdade material, "segundo o qual o igual, em todos os aspectos relevantes, deve ser tratado de forma igual e o desigual de forma desigual" (HABERMAS, 2001, p. 297 , n.t.). O modo de definição de ditos "aspectos relevantes" é reconstruído por Habermas como uma disputa histórico-política dos cidadãos, no uso de sua autonomia pública, pela interpretação mais adequada dos critérios definidores do que venha a ser, em cada momento, o tratamento igual de si próprios perante o ordenamento jurídico, na condição de destinatários do sistema de direitos - autonomia privada. Esse processo tomaria a forma social de uma "dialética entre igualdade jurídica e igualdade fática", ilustrada pelo filósofo do discurso a partir da luta histórica das mulheres pela igualdade de direitos, em que os movimentos feministas, adotando uma postura democrático-procedimental e, assim, rompendo com os paradigmas jurídico-políticos anteriores - liberal e de Estado social - que reduziam as mulheres à condição de meras destinatárias de direitos ou programas sociais, assumem as rédeas do processo político e passam a insistir:

em que se devem esclarecer junto à opinião pública de caráter político, ou seja, em um debate público acerca da interpretação adequada das carências, os "enfoques" sob os quais as diferenças entre experiências e situações de vida de determinados grupos de homens e mulheres se tornam significativos para um uso das liberdades de ação em igualdade de chances (HABERMAS, 2007, p. 245).

Desse modo, tendo em vista que a ética discursiva habermasiana, distanciando-se da tradição universalista, abrese a uma definição da igualdade de tratamento - universalidade igualitária - a partir da perspectiva dos próprios sujeitos concernidos, que poderiam interferir diretamente no processo 
reflexivo-hermenêutico de autodeterminação e autocompreensão de uma comunidade política, restaria saber se o próprio Habermas não chegaria, assim, a uma solução satisfatória para o conflito entre as perspectivas da universalidade e do cuidado assimétrico frente às necessidades do outro concreto, tanto a partir de um prisma normativo-social mais geral, quanto, mais especificamente, a partir de uma visão interna do campo de aplicação do Direito.

O problema relativo à primeira dessas questões, de cunho mais amplo, corresponde, com efeito, a parte do objeto da preocupação teórica de Honneth em seu "The Other of Justice", sendo abordado no momento em que o filósofo do reconhecimento compara o alcance normativo da ética derridiana com aquele da ética discursiva habermasiana. Segundo pondera, Habermas tentou realizar uma mediação entre os princípios da justiça universalista e do cuidado irrestrito com o outro a partir de um terceiro princípio, o da solidariedade, que o teórico do discurso também denomina "o outro da justiça". Este compartilharia com o dever irrestrito de cuidado "uma preocupação com o destino existencial de outros seres humanos, uma preocupação que chegaria ao nível da afetividade" (HONNETH, 2007b, p. 123, n.t.), mas que daquele diferiria porque "se aplica a todos os seres humanos sem qualquer privilégio ou assimetria" (HONNETH, 2007b, p. 123, n.t.). Para Habermas, aduz Honneth, o princípio da solidariedade teria incidência em "todo discurso prático, porque os participantes devem reconhecer uns aos outros não apenas como pessoas iguais, mas também como indivíduos irrepresentáveis" (HONETH, $2007 b$, p. 123 , n.t.).

Honneth, todavia, além de indagar sobre quais experiências e motivações tornariam tal parâmetro normativo de solidariedade plausível na realidade social, ainda vai criticamente chamar atenção para a circunstância de que nem a igualdade de tratamento, nem a solidariedade, carregam em sua natureza normativa o caráter unilateral, ou não recíproco, que se encontra associado à ideia de cuidado. É, portanto, realçando o sentido particular deste último princípio que o filósofo do reconhecimento vai dizer que "não se pode esperar de qualquer ser humano que ele assuma tal forma 
de responsabilidade da mesma maneira que se espera que todos os seres humanos demonstrem respeito pela dignidade de cada indivíduo" (HONNETH, 2007b, p. 124, n.t.).

As considerações de Honneth são importantes porque lançam luz sobre um certo "silêncio eloquente" - com seus próprios pressupostos - por parte da ética do discurso habermasiana com relação ao lugar que a ideia de cuidado irrestrito poderia ter em seu arcabouço teórico-moral. A recusa a um tratamento normativo mais consequente desse conceito, sem dúvida, se relaciona ao vínculo que Habermas mantém, não obstante seus progressos, com a tradição do universalismo kantiano, associado a um racionalismo que prioriza a dimensão epistemológico-cognitiva proporcionada pela lógica pragmática da argumentação. Destaquese que mesmo a abertura democrático-procedimental da ética do discurso a valores e interesses não universalizáveis se mantém normativa e cognitivamente vinculada ao terreno dos pressupostos comunicativos e das regras de argumentação. Por isso, vale ainda observar que a atração exercida sobre Honneth pela ética desconstrucionista de Derrida, em detrimento de alguns elementos da habermasiana, não decorreu apenas de sua preocupação com o singular ou com o "outro concreto", mas do caráter irrestrito, assimétrico, afetivo, não discursivo, que a responsabilidade gerada por aquela preocupação apresenta.

Já da segunda questão se cuidará na última seção, entendendo-se que, embora destoem em suas respostas à questão mais geral - estado da relação entre justiça e cuidado sob uma ótica sócio-normativa ampliada -, Habermas e Honneth oferecem uma abordagem aproximada sobre a relação desses dois princípios no âmbito jurídico. De forma mais direta, é possível dizer que ambos excluem o princípio do cuidado assimétrico do campo de aplicação do Direito, razão pela qual será necessário retomar, primeiramente, alguns contornos da relação entre Direito e justiça na ética desconstrucionista de Derrida para que, somente em um segundo passo, se torne possível esboçar uma tentativa de resposta adequada àquela questão. 
|164|

Entre Habermas e Derrida:...

2. A tensão insolucionável, mas produtiva, entre os princípios de justiça

Como já foi dito na introdução, Honneth considera equivocada a ligação estabelecida por Derrida entre a ideia de cuidado e a esfera de aplicação das normas jurídicas, que teria início por uma má compreensão do último quanto às bases morais de justificação do Direito na modernidade. Além de passar por alto do conteúdo universalista das relações legais, o desconstrucionista não teria se atentado para o fato de o Direito possuir em sua própria estrutura normativo-institucional mecanismos, como a equidade, que já permitiriam um tratamento tão compreensivo quanto possível da particularidade de cada caso individual, sem precisar com isso recorrer à perspectiva externa, não fundamentável em suas próprias bases normativas, do cuidado ou da bondade.

É preciso notar, primeiramente, que Honneth, em sua reconstrução do modelo ético derridiano, faz a opção expressa por não retomar os fundamentos teórico-normativos em que o desconstrucionista alicerça sua compreensão do Direito positivo, ficando sua análise restrita ao modo como a questão da justiça é trabalhada nos contextos de aplicação jurídico-normativa (HONNETH, 2007b, p. 116). Tal escolha torna mais curto o percurso honnethiano tanto para as críticas que dirige a Derrida quanto para a "reconciliação" que faz entre a ética desconstrucionista e a ética discursiva sobre a base normativo-conceitual de sua teoria do reconhecimento (HONNETH, 2003) - que nesse texto sempre permanece no plano de fundo -, mas não sem consequências, pois muitas das explicações e justificativas oferecidas pelo filósofo desconstrucionista para demonstrar a relação conflituosa estabelecida entre Direito (universalidade) e justiça (cuidado) são perdidas nesse processo.

Um dos conceitos omitidos por Honneth, talvez o mais importante, é o de "experiência de aporia" ou "experiência do impossível", que, no modelo desconstrucionista, além de explicar a própria ideia de justiça, opera como chave de leitura da interação antagônica entre justiça e Direito. Conforme Derrida, 
“a justiça é uma experiência do impossível. Uma vontade, um desejo, uma exigência de justiça cuja estrutura, não fosse uma experiência da aporia, não teria nenhuma chance de ser o que ela é, a saber, apenas um apelo à justiça" (DERRIDA, 2007, p. 30). Essa colocação, de tom polêmico, traz como premissa o entendimento de que Direito e justiça correspondem a fenômenos essencialmente distintos, embora complementares, em um sentido diverso daquele concebido pela ética do discurso: o Direito, para Derrida, insere-se na esfera do calculável, do simétrico, do finito e do desconstruível, ao contrário da justiça, que ele descreve como assimétrica, inapresentável e indesconstruível, movimentandose no próprio nível, que se poderia chamar com Critchley (2014, p. 273) de quase-transcendental, da desconstrução.

Assim, contrariando Habermas, por exemplo, que ainda vê no Direito moderno um momento de incondicionalidade ou não instrumentalização, Derrida atribui à estrutura interna da ordem jurídica apenas uma conexão sistemática com manifestações simbólicas de violência. Seu argumento é de que a facticidade da imposição jurídico-estatal apenas encontra "justificação" na violência performativa da autofundação, "que nenhuma justiça, nenhum direito prévio e anteriormente fundador, nenhuma fundação preexistente, por definição, poderia nem garantir nem contradizer ou invalidar" (DERRIDA, 2007, p. 24), fenômeno que ele, acompanhando Montaigne, chama de "fundamento místico" da autoridade da lei. No ato de imposição do Direito, misturarse-iam a violência da ruptura com a ordem anterior e a violência de um "nós" que submete a si toda expressão de singularidade ou diferença. ${ }^{7}$

\footnotetext{
${ }^{7}$ Ele cita, por exemplo, o caso da imposição de uma língua a minorias nacionais ou étnicas (DERRIDA, 2003, p. 37-38). Essa leitura derridiana é diretamente criticada, a partir de uma perspectiva ético-discursiva, por Seyla Benhabib (2006), quem, não obstante considere fundamental a percepção do caráter excludente de todo ato de constituição ou fundação de uma ordem jurídica, chama atenção para o fato de o desconstrucionista não notar a natureza ambivalente desse processo. Ao concentrar-se na violência do ato performativo, Derrida não consideraria, por um lado, a ruptura
} 
$|166|$

Entre Habermas e Derrida:..

Em vista desse quadro, o desenvolvimento da ideia derridiana de justiça acaba percorrendo um caminho que ele próprio descreve como oblíquo. Diferentemente do Direito, ela não se constituiria em um fato, em presença, mas seria apenas um apelo, um desejo, que em cada situação historicamente delimitada de decisão judicial, a despeito ou mesmo em razão da universalidade normativa, sobreviria como exigência de responsabilidade incondicional pela alteridade, pela infinidade do outro e, dentro desse sentido, pela singularidade de cada caso. A historicidade e a finitude da norma, ou do ato performativo, seriam sempre contrapostas pelo "evento", por aquilo que excede a previsão, que não pode ser calculado nem aprisionado no discurso (DERRIDA, 2006). Nesse sentido é que a justiça se constitui, para Derrida, em uma "experiência do impossível", pois, embora ela se coloque, no momento da decisão, no horizonte de possibilidade do intérpreteaplicador, abrindo "ao porvir a transformação, a refundição ou a refundação do direito e da política" (DERRIDA, 2007, p. 55), nunca se poderá qualificar uma decisão como justa. No momento em que o ato decisório é alcançado, se estabelece, segundo esse modelo, um novo performativo, um novo dogmatismo, em si neutralizador da alteridade e, portanto, sujeito à desconstrução.

Depossedessas definiçõesedistinções, torna-sepossívelagora retomar a crítica honnethiana ao modelo ético desconstrucionista. E a primeira conclusão que se coloca é a de que Honneth se equivocou ao atribuir a Derrida um suposto desconhecimento dos fundamentos normativos do Direito moderno. Como se pode retirar das explicações anteriores, justamente por tomá-los em conta é que o desconstrucionista desenvolveu uma concepção alternativa de justiça, tentando desvencilhá-la da violência simbólica, no seu entender, subjacente ao caráter performativo das normas jurídicas. Manter a universalidade, ou a igualdade jurídica, como prisma exclusivo na aplicação das leis significa, para Derrida, reter-

emancipatória com os fundamentos teológicos e cosmológicos, trazida pelas modernas concepções de legitimidade democrática, e, por outro, a introdução de uma lógica de legitimação universalista no percurso histórico ocidental. 
se na ordem do cálculo, do programável ou, em última instância, do ato performativo. A responsabilidade pela infinidade do outro se mostraria, nesses termos, como a única compreensão possível de justiça, embora, ao mesmo tempo, o filósofo desconstrucionista destaque a impossibilidade de que ela venha a se fazer presente.

Seguramente, as reservas derridianas quanto à universalidade jurídica poderiam ser contrapostas pelos avanços normativo-conceituais trazidos pela perspectiva intersubjetiva da ética do discurso. Contudo, o que se teria com isso, em um primeiro momento, seriam apenas duas compreensões filosóficas concorrentes acerca da justiça e da própria noção de intersubjetividade (CRITCHLEY, 2006), e não, como indicado por Honneth, um simples erro de localização, por parte Derrida, do campo adequado de justificação da perspectiva da responsabilidade assimétrica pelo outro concreto. É necessário ter essa diferença de leituras em mente para que seja compreendido o grau de limitação que a reconstrução honnethiana impôs ao modelo ético desconstrucionista.

Portanto, o trabalho de Honneth em seu "The Other of Justice" não se resumiu a uma cartografia de princípios da justiça, mas consistiu em uma verdadeira tentativa de reconciliação - que ele próprio chega a imputar a Habermas (cf. HONNETH, 2007b, p. 123) - de sistemas filosóficos avessos: o da ética do discurso, fundado em uma concepção de intersubjetividade simétrica, e o da ética desconstrucionista, fundado em uma concepção de intersubjetividade assimétrica (CRITCHLEY, 2006). No próprio artigo não ficam totalmente claros os pressupostos teóricos sobre os quais Honneth procedeu a essa reconstrução, havendo apenas alguns indícios, como na passagem final, quando ele afirma que o princípio do cuidado, ao lado da solidariedade, configura um contraponto normativo ao princípio da justiça - da universalidade -, e, nesse sentido, lhe é suplementar (HONNETH, 2007b, p. 125). Aqui a conexão com a sua teoria do reconhecimento (HONNETH, 2003) se mostra inevitável, especificamente com relação ao que ele considera as três esferas básicas de reconhecimento social: do amor, do Direito e da solidariedade. 
$\mid 168$ |

Entre Habermas e Derrida:...

Em um desenvolvimento posterior de seu modelo crítico, Honneth veio a estabelecer que a cada esfera de reconhecimento social - relações familiares íntimas, relações jurídicas e relações sociais de trabalho -, resultantes do processo de diferenciação da sociedade capitalista, corresponde um princípio normativo de reconhecimento - necessidade, igualdade e mérito. Isso porque:

\begin{abstract}
enquanto nas relações jurídicas democráticas é a igualdade deliberativa de todos os sujeitos que forma a base normativa do respeito assegurado entre os participantes, na relação interna da família o são as necessidades particulares de cada um de seus membros e na relação social de trabalho o são os desempenhos individuais dos participantes que servem como pontos de referência do reconhecimento (HONNETH, 2009, p. 365).
\end{abstract}

Com essas indicações, torna-se um pouco mais clara a orientação tomada por Honneth ao reconduzir o princípio da responsabilidade assimétrica pelo outro concreto à esfera da afetividade. Todavia, embora não se discorde em linhas gerais da base conceitual-normativa da teoria do reconhecimento, que por si já consegue ir além da ética do discurso em questão de amplitude no tratamento da complexidade normativa e dos elementos motivacionais que compõem a moralidade social, o mesmo não se pode dizer quanto à opção teórica honnethiana por excluir conceitualmente a tensão entre igualdade e cuidado do campo de aplicação do Direito.

A tensão insolucionável, mas produtiva, entre esses princípios, que Honneth, no "The Other of Justice", avalia positivamente como um ganho trazido pelo modelo ético desconstrucionista, recebe restrições quando, no mesmo texto, ele passa a tratar da esfera específica de incidência de cada princípio ${ }^{8}$

${ }^{8}$ É importante observar que Honneth, no desenrolar de seu empreendimento intelectual, tornou menos rigorosa essa delimitação entre campos de incidência do cuidado e da igualdade de tratamento, como é possível verificar, por exemplo, em Honneth (2007a) 
- cuidado/família, igualdade/direito -, onde aquelas orientações normativas seriam, na sua ótica, "reciprocamente excludentes" (HONNETH, 2007b, p. 124). Sobre esse ponto, é importante a observação crítica de Sinnerbrink, para quem:

a asserção abrupta de Honneth, no sentido de uma oposição excludente entre cuidado e igualdade no "The Other of Justice", joga contra a confiabilidade de seu argumento de que cuidado e igualdade permanecem em uma relação tensa de suplementação mútua. Essa ambiguidade entre cuidado e reconhecimento na abordagem de Honneth, eu argumentaria, indica que a perspectiva do cuidado assimétrico, como o "outro da justiça", também propõe um desafio ético à teoria do reconhecimento (SINNERBRINK, 2011, p. 202, n.t.).

Além de se mostrar excessivamente rigorosa e, assim, distante da prática social, essa limitação abrupta colocada por Honneth quanto à tensão entre princípios na esfera em que um deles se apresenta como soberano, ${ }^{9} \mathrm{em}$ um sentido mais específico, se mostra prejudicial a uma tentativa de apreensão mais complexa das bases normativas envolvidas nos contextos de aplicação do Direito. Seguindo-se um caminho diverso do de Honneth, parece plausível buscar uma releitura da "experiência do impossível" da justiça derridiana, como uma tensão insolucionável e produtiva entre princípios de justiça, nos próprios contextos de aplicação jurídico-normativa, empreendimento cujos traços iniciais serão avançados na próxima seção.

ou Honneth (2004). Contudo, ainda não há indícios de que ele tenha reformulado essa compreensão com respeito à relação entre princípios de reconhecimento no campo jurídico.

${ }^{9}$ A ideia de soberania dos princípios de reconhecimento aparece, por exemplo, em Honneth (2004). 
| 170 |

Entre Habermas e Derrida:..

3. A tensão produtiva entre princípios de reconhecimento no interior do campo jurídico: elementos para uma crítica dos discursos de aplicação do Direito

É possível, agora, retomar a última questão colocada na parte final da primeira seção deste artigo - sobre ser possível alcançar uma abordagem adequada para o conflito entre igualdade de tratamento e cuidado infinito, no interior dos contextos de aplicação do Direito, a partir da ética discursiva habermasiana - e, assim, prosseguir para o desfecho da proposta reconstrutiva aqui empreendida. Como de certa maneira se adiantou lá, Habermas, até mesmo de forma mais coerente com os pressupostos de seu empreendimento teórico do que Honneth com os seus, limita a perspectiva de análise crítica da decisão jurídico-normativa ao prisma da igualdade de tratamento, que nos discursos de aplicação adquire a forma de um princípio de adequabilidade. Isso porque, nesse contexto, a legitimidade discursiva se mediria pela qualidade de uma descrição completa dos sinais característicos situacionais e de uma reconstrução coerente do sistema de normas prima facie aplicáveis, a partir da ótica argumentativa daquelas pessoas concretamente afetadas pela decisão. ${ }^{10}$ Apesar de não excluir que sentimentos de empatia venham à tona nos contextos de aplicação de normas, ${ }^{11}$ a ética do discurso habermasiana não credita maior relevância à perspectiva crítica que o "outro concreto", compreendido sob a ótica da singularidade afetiva, e a correspondente obrigação de cuidado assimétrico que ele traz, podem oferecer. ${ }^{12}$

\footnotetext{
${ }^{10}$ Cf. Habermas (2001) e Günther (1993).

${ }^{11}$ Para uma análise da relação entre empatia e adequabilidade no interior dos discursos de aplicação, ver o ótimo estudo de Rehg (1994). Ele, todavia, tenta adequar a tensão entre essas noções dentro dos próprios pressupostos universalistas da ética do discurso, limitando a perspectiva de análise, assim como a compreensão, das bases normativas envolvidas.

${ }^{12}$ Habermas justifica sinteticamente sua posição da seguinte maneira: "Certamente a função judicial consiste em aplicar as leis de modo que se ajustem ao caso
} 
Em contrapartida, dentro da própria vertenteético-discursiva, que não se limita à versão habermasiana, há desenvolvimentos, como aqueles das teóricas feministas, que se revelam mais promissores para uma abordagem crítica e produtiva da relação entre cuidado assimétrico e universalidade igualitária no interior da esfera jurídica. Young (1991) e Benhabib (1991), por exemplo, embora avaliem positivamente alguns elementos importantes do modelo ético de Habermas, especialmente os relacionados à inclusividade participativa nos processos discursivos, são ao mesmo tempo sérias críticas dessa proposta por afastar as manifestações de afetividade, assim como a expressão corporal, da esfera moral. Em reflexão importante, assevera Benhabib que:

As necessidades, bem como emoções e afetos, tornamse meramente dadas propriedades de indivíduos, que a filosofia moral repugna examinar, com base em que isso pode interferir na autonomia do eu soberano. As mulheres, pelo fato de terem sido transformadas em "zeladoras domésticas das emoções" no mundo burguês moderno, e porque têm sofrido por causa das incontidas necessidades e fantasias da imaginação masculina, que as transformou ao mesmo tempo em Mãe Terra e megera implicante, a Virgem Maria e a prostituta, não podem condenar essa esfera ao silêncio (BENHABIB, 1991, p. 106).

concreto em relação com as 'circunstâncias particulares'. [...] Caso contrário, não se poderia encontrar a única norma 'adequada', muito menos se poderia aplicá-la com suficiente 'flexibilidade'. Contudo, as exigências individuais dos sujeitos de direito estão de certa maneira predeterminadas pelos predicados da norma jurídica, estão fundamentalmente limitadas àquilo que os sujeitos de direito podem esperar uns dos outros: um comportamento que, em última instância, se pode impor e que se enquadre nas determinações formais do Direito. As normas jurídicas regulam relações interpessoais entre atores que se reconhecem como membros de uma comunidade abstrata, isto é, que somente se estabelece, por sua vez, a partir de normas jurídicas" (HABERMAS, 2006, p. 283-284, n.t.). 
$\mid 172$ |

Entre Habermas e Derrida:...

Esse relato crítico da autora feminista, não obstante dirigido ao campo do discurso ético, levanta um argumento crucial em favor da abertura ao "outro concreto", que pode também ser empregado contra a tentativa de afastamento do cuidado assimétrico do campo jurídico-aplicativo. Como ela ressalta, a exclusão da narrativa de base afetiva e a restrição do discurso à dimensão cognitiva dos argumentos contribuem para a manutenção de formas seculares de dominação de gênero, problema que, quando incide na seara do Direito, coloca em xeque a própria pretensão igualitáriomaterialista ligada à validade das normas jurídicas modernas.

Nesse ponto, torna-se importante retornar a Honneth para esclarecer, primeiramente, que ele, quando se refere ao princípio da responsabilidade infinita com relação ao outro concreto, não está pensando somente na abertura hermenêutico-discursiva à ótica do particular, mas, de forma mais profunda, na assimetria ou unilateralidade de obrigações desenvolvidas na esfera onde esse princípio é soberano - do amor. ${ }^{13}$ Por essa razão, ainda se deve explicar que a reconstrução teórico-normativa dos contextos de aplicação do Direito que aqui se propõe, embora contrarie em alguma medida a leitura honnethiana, não objetiva uma troca ou amálgama de critérios de justiça, ou mesmo a proposição de uma concorrência normativa, em paridade de condições, entre igualdade de tratamento e cuidado infinito no campo do Direito. A diferenciação das esferas de reconhecimento, verificada com a transição para a modernidade, está entre os pressupostos teóricosociais deste trabalho, assim como a reconstrução normativa que Honneth faz das perspectivas do cuidado assimétrico e da universalidade como dois princípios de justiça social ou de reconhecimento.

O que se pretende defender, na verdade, é que o cuidado assimétrico com relação ao "outro concreto" incide também como uma "experiência do impossível", ou, de forma mais exata, uma

\footnotetext{
${ }^{13}$ Provavelmente sua restrição quanto à incidência do cuidado assimétrico na esfera jurídica venha daí, como já indicado na seção anterior.
} 
perspectiva crítica, como defende Benhabib,${ }^{14}$ no campo de aplicação jurídico-normativa. Conquanto as restrições colocadas pelas características formais do Direito não permitam que o princípio do cuidado obtenha um grau satisfatório de realização nessa área, uma exigência de abertura mínima a formas de expressão típicas da esfera do amor - corporal, sentimental-afetiva, narrativa, etc. -, como resultado de sua órbita e constante pressão sobre a esfera público-jurídica, pode oferecer ao teórico/participante crítico incursões e visões importantes acerca de bloqueios institucionais ou prático-discursivos com relação à necessidade assimétrica do "outro concreto", que em última instância vêm a afetar a própria pretensão normativa da igualdade de tratamento.

A "simples" garantia de participação e argumentação no processo judicial, por exemplo, não assegura que a parte, em qualquer contexto, seja realmente "ouvida". Basta pensar em casos de tortura, estupro ou maus tratos, em que o "excesso de realidade" sofrido por quem vivenciou uma experiência traumática pode ter levado à "destruição do consciente e da capacidade de discernimento entre o real e o irreal" (SELIGMANN-SILVA, 2000, p. 92). Em tais casos, somente abrindo espaço para formas da expressão da particularidade que vão além do processo argumentativo se pode conseguir algum êxito no acesso a "vozes" que, normalmente, só teriam ressonância na esfera de reconhecimento do amor. ${ }^{15}$

\footnotetext{
${ }^{14}$ Benhabib (1991, p. 103), por exemplo, adota o ponto de vista do outro concreto como "um conceito crítico que designa os limites ideológicos do discurso universalista. Significa o não pensado, o não visto e o não ouvido nessas teorias”.

${ }^{15}$ É importante lembrar que crimes de maus tratos e de tortura, na concepção de Honneth (2003, p. 215), além de violarem direitos universais, ainda alcançam a própria esfera da autoconfiança psíquica, relacionada ao princípio do cuidado. Nesse sentido, ele acrescenta que "a particularidade dos modos de lesão física, como ocorrem na tortura ou na violação, não é constituída [...] pela dor puramente corporal, mas por sua ligação com o sentimento de estar sujeito à vontade de um outro, sem proteção, chegando à perda do senso de realidade” (HONNETH, 2003, p. 215).
} 
|174 |

Entre Habermas e Derrida:...

Sobre bloqueios institucionais, em tempos de vídeoconferência, caberia indagar até que ponto a ausência de contato direto com a parte não prejudicaria a percepção de sua narrativa pessoal, o acesso à sua perspectiva única e insubstituível. Indo mais além e alcançando o caso específico do teleinterrogatório, em que o réu é ouvido no próprio presídio, sem contato direto com o juiz, poder-se-ia perguntar, por exemplo, em que medida não ficaria prejudicada a identificação de casos de tortura cometidos por policiais e agentes penitenciários, onde, além do trauma da vítima, ainda se tem a ausência do contato "face a face".

Assim, este artigo conclui sua reflexão defendendo que, da mesma maneira que o discurso jurídico-universalista pode ajudar a lidar com problemas de um "convencionalismo do cuidado" no campo da família, como Honneth chega a defender (HONNETH, 2007a), no campo jurídico a manutenção da perspectiva da afetividade, como "experiência do impossível" nessa esfera social, pode oferecer elementos importantes para uma crítica dos discursos de aplicação do Direito. Nesse sentido, além de contribuir para a realização de diagnósticos de bloqueios e formas de dominação comunicativa, a própria manifestação do "outro concreto" pode ganhar maior expressividade, possibilidades que restariam seriamente comprometidas pela restrição à perspectiva unilateral do universalismo-igualitário conectada à forma jurídica.

\section{Referências}

APEL, Karl-Otto. Dissolução da Ética do Discurso. In: MOREIRA, Luiz (org.). Com Habermas, contra Habermas: Direito, Discurso e Democracia. Trad. Luiz Moreira. São Paulo: Landy Editora, 2004.

BENHABIB, Seyla. Democracy and Difference: Reflections on the Metapolitics of Lyotard and Derrida. In: THOMASSEN, Lasse (org.). The Derrida-Habermas Reader. Chicago: The University of Chicago Press, 2006, p. 128-156. 
. O outro generalizado e o outro concreto: a controvérsia Kohlberg-Gilligan e a teoria feminista. In: BENHABIB, Seyla; CORNELL, Drucilla (orgs.). Feminismo como crítica da modernidade. Trad. Nathanael da Costa Caixeiro. Rio de Janeiro: Rosa dos Tempos, 1991, p. 87-106.

CENCI, Angelo Vitorio. Da ética do discurso à teoria do discurso. In: NOBRE, Marcos; REPA, Luiz (orgs.). Habermas e a reconstrução. Campinas: Papirus, 2012.

CRITCHLEY, Simon. Frankfurt Impromptu - Remarks on Derrida and Habermas. In: THOMASSEN, Lasse (org.). The DerridaHabermas Reader. Chicago: The University of Chicago Press, 2006, p. 98-110.

DERRIDA, Jacques. Força de lei: o fundamento místico da autoridade. Trad. Leyla Perrone-Moisés. São Paulo: WMF Martins Fontes, 2007.

- Performative Powerlessness: A Response to Simon Critchley. In: THOMASSEN, Lasse (org.). The Derrida-Habermas Reader. Chicago: The University of Chicago Press, 2006, p. 111114.

GÜNTHER, Klaus. The Sense of Appropriateness: Applications Discourses in Morality and Law. Trad. John Farrell. New York: State University of New York Press, 1993.

HABERMAS, Jürgen. Facticidad y validez: sobre el derecho y el Estado democrático de derecho en términos de teoría del discurso. Trad. Manuel Jimenéz Redondo. Madri: Trotta, 2001.

Consciência moral e agir comunicativo. Trad. Guido Antônio de Almeida. 2. ed. Rio de Janeiro: Tempo brasileiro, 2003.

Verdade e justificação: ensaios filosóficos. Trad. Milton Camargo Mota. São Paulo: Loyola, 2004.

. Tratamiento cultural igualitario y los límites del liberalismo postmoderno. In: Entre naturalismo y religión. Trad. Daniel Gamper. Barcelona: Paidós, 2006, pp. 275-314. 
A inclusão do outro: estudos de teoria política. Trad. Milton Camargo Mota, Paulo Astor Soethe, George Sperber. $2^{\underline{a}}$ ed. São Paulo: Loyola, 2007.

HONNETH, Axel. Luta por reconhecimento: a gramática moral dos conflitos sociais. Trad. Luiz Repa. São Paulo: Editora 34, 2003.

Recognition and Justice: Outline of a Plural Theory of Justice. Trad. Andrew Inkpin. Acta Sociologica, vol. 47, n. 4, p. 352-364, 2004.

Between Justice and Affection: The Family as a Field of Moral Disputes. In: Disrespect: The Normative Foundations of Critical Theory. Trad. John Farrell. Cambridge: Polity Press, 2007a, p. 143-162.

The Other of Justice: Habermas and the Ethical Challenge of Postmodernism. In: Disrespect: The Normative Foundations of Critical Theory. Trad. John Farrell. Cambridge: Polity Press, 2007b, p. 99-128.

A textura da justiça: sobre os limites do procedimentalismo contemporâneo. Trad. Emil Albert Sobottka. Civitas, v. 9, n. 3, p. 345-368, 2009.

HULSHOF, Monique; KEINERT, Maurício Cardoso; MELO, Rúrion Soares. Diferenciação e complementariedade entre direito e moral. In: NOBRE, Marcos; TERRA, Ricardo (orgs.). Direito e Democracia: um guia de leitura de Habermas. São Paulo: Malheiros, 2008, p. 74-90.

REHG, William. Insight \& Solidarity: The Discourse Ethics of Jürgen Habermas. Berkeley: University of California Press, 1994.

SELIGMANN-SILVA, Márcio. História como trauma. In: SELIGMANN-SILVA, Márcio; A. NESTROVSKI, Arthur (orgs.). Catástrofe e representação. São Paulo: Escuta, 2000, p. 73-98.

SINNERBRINK, Robert. Power, Recognition, and Care: Honneth's Critique of Poststructuralist Social Philosophy. In: 
PETHERBRIDGE, Danielle (org.). Axel Honneth: Critical Essays. Leiden: Koninklijke Brill NV, 2011, p. 177-206.

WHITE, Stephen K. (org.). The Cambridge Companion to Habermas. Cambridge: Cambridge University Press, 1995, p. 289323.

YOUNG, Iris Marion. A imparcialidade e o público cívico: algumas implicações das críticas feministas da teoria moral e política. In: BENHABIB, Seyla; CORNELL, Drucilla (orgs.). Feminismo como crítica da modernidade. Trad. Nathanael da Costa Caixeiro. Rio de Janeiro: Rosa dos Tempos, 1991, p. 66-86. 